\title{
Sobre el juego en Winnicott
}

\author{
Brianda Portalatin Vargas ${ }^{1}$ \\ London, U.K.
}

El juego en la comprensión de Winnicott va más allá de la "técnica". Da lugar a pensar la experiencia del paciente y del analista. El juego es un vehículo de la esperanza y tiene impacto en el propio análisis. En el playing Winnicottiano el foco no es el contenido del juego, sino del jugar mismo, del descubrimiento de una nueva experiencia en un marco especializado entre los componentes de la díada.

Palabras clave: Winnicott, Juego, Relacional, Encuadre.

Playing in Winnicott's understanding goes beyond the "technique". It allows us to think about the patient and the analyst experience. Playing is a vehicle of hope and has an impact on the analysis itself. In Winnicottian playing the focus is not the content of the play, but of the play itself, the discovery of a new experience within a specialized framework among the components of the dyad.

Key Words: Winnicott, Play, Relational, Setting, Framework.

English Title: About playing in Winnicott

\section{Cita bibliográfica / Reference citation:}

Portalatin Vargas, B. (2020). Sobre el juego en Winnicott. Clínica e Investigación Relacional, 14 (1): 163-184. [ISSN 1988-2939] [Recuperado de www.ceir.info ] DOI: 10.21110/19882939.2020.140110

\footnotetext{
${ }^{1}$ Licenciada en Psicología en la Universidad Pontificia Comillas. Máster en Psicología General Sanitaria (UPC) y en Psicoterapia psicoanalítica (UCM). Contacto: Correo electrónico: brianda.portalatin@gmail.com
} 


\section{$80)$ Introducción $\circlearrowleft 3$}

Igual que los pequeños aprendemos el lenguaje de nuestros padres, los pacientes aprenden el lenguaje de su analista, porque desean ser comprendidos (Balint, 1982). También Coderch (2007) defiende que la primera e ineludible satisfacción que precisa todo paciente es que sus necesidades sean escuchadas y comprendidas, incluso aunque no sean satisfechas.

Dice Balint que los analistas tienen que aceptar ciertos modos de comunicación diferentes de la palabra (1982). Tenemos que escuchar el material verbal y el no verbal ya que el infante ${ }^{1}$, no se comunicará con nosotros mediante nuestro lenguaje adulto ${ }^{2}$, porque el lenguaje del niño es el juego.

Valeros (1997) repara en como la palabra vincula (significa) relaciones previas más circunscriptas y de otra naturaleza, pero su aparición y su cometido de dar significado son posteriores en el desarrollo. Antes que lo verbal, las experiencias están organizadas en otras modalidades no verbales.

Si todo marcha bien, el paciente aprenderá de nosotros como nosotros de él, pero únicamente si somos capaces de desarrollar un lenguaje específico e individual. De limitarnos al lenguaje verbal, la brecha puede ser insalvable, es por esto que habremos de aceptar y salir al encuentro de otros modos de comunicación diferentes de la palabra.

\section{sos El Juego @s}

Bollas (2009), que ha trabajado con niños autistas y esquizofrénicos, nos comunica que:

"El niño autista no puede decirnos cómo se siente ni indicarnos la constitución de su psique; solo puede mostrarnos todo eso, y lo hace muy bien si el clínico admite ser usado como un objeto y guiado a través de su propio mundo interno por entre la memoria que el sujeto guarda de sus relaciones de objeto".

Consideramos que el niño, comúnmente denominado "sano" (o al menos no tan severamente sufriente como el aquejado por las patologías trabajadas por Bollas), también se comunica con nosotros mediante un proceso muy similar si somos capaces de comprender.

Los niños juegan, necesitan jugar para no enfermar, apunta Tagle (2016) y si no juegan es porque ya están enfermos. Aunque es a partir de Winnicott que nuestras ideas sobre el juego se transforman, ya Freud había reparado en la importancia de las "realidades alternativas" y en las posibilidades sublimatorias que estas nos ofrecen. Nos confía su convicción en la 
existencia de medios suficientes para transformar en objeto del recuerdo y de elaboración anímica lo que en sí mismo es displacentero.

Freud (1920) se percata de cómo Los niños repiten en el juego todo cuanto les ha hecho gran impresión en la vida; de ese modo abreaccionan la intensidad de la impresión y se adveñan, por así decir, de la situación. No pasó por alto el ineludible hecho de que la partida es necesaria para celebrar el regreso 3 : ... recibimos la impresión de que el niño convirtió en juego esa vivencia a raíz de otro motivo. En la vivencia era pasivo, era afectado por ella; ahora se ponía en un papel activo repitiéndola como juego, a pesar de que fue displacentera Freud (1920).

El mecanismo de revivir lo vivido pasivamente de manera activa condensado en la cuestión del Fort-Da. Freud (1920) ejemplifica como al tornar en activo lo experimentado pasivamente, el niño se apropia de su vivencia y esta trasformación le ayuda a digerirlo. Freud hizo quedar constancia de este mágico proceso que tiene lugar en el jugar.

Green (2012) repara en que la elaboración imaginativa está muy ligada a la ausencia, es la que cimienta el desarrollo emocional y físico, ambos ineludiblemente enlazados ya que nuestra psique es lo que resulta de la relación entre dos cuerpos, uno de los cuales está ausente.

Winnicott (1971) presenta el caso de una mujer que, en la primera parte de sus sesiones, procuraba mostrarle como era cuando estaba sola, pero sin palabras. Esta paciente solía utilizar muchos espejos, con la finalidad de encontrar(se) alguien reflejado. "Había estado mostrándome, pero aunque me encontraba ahí, nadie me devolvía el reflejo". Winnicott le dijo que ella existía en la búsqueda (antes que en el encontrar o en ser encontrada). Esta paciente podía buscarse porque la búsqueda solo puede gestarse en el ámbito de lo informe "o quizá de un juego rudimentario, como en una zona neutral".

Aquello que ese encuentra inconexo puede integrarse al ser reflejado y decantar finalmente en un sentimiento de "mismidad", en la sensación de la persona de "ser". "Únicamente ahí, en ese estado no integrado de la personalidad, puede aparecer lo que denominamos creativo".

Así, una de las cosas (más valiosas) que ofrecemos en terapia es el sostenimiento de la experiencia informe (y de los impulsos creadores, que conjuntamente son la), base de la experiencia. Winnicott (1971) dirá:

Experimentamos en la zona de los fenómenos transicionales, en el estimulante entrelazamiento de la subjetividad y la observación objetiva, zona intermedia entre la realidad interna del individuo y la realidad compartida del mundo, que es exterior a los individuos. 
Nuestro cometido es abordar el drama del sujeto en la transferencia, como indicaría Bollas (2009), y el carácter de la parte de la psique que vive en el mundo sin palabras.

De nuevo Bollas (2009, en la introducción) puede ayudarnos:

"Un niño autista tal vez no profiera una palabra, pero su lenguaje son sus gritos, su denso y preocupado silencio, y su uso mimético de las personas. Él se aloja dentro del otro y lo compele a experimentar la quiebra del lenguaje (y la esperanza, y el anhelo)".

Tal vez por la mayor cercanía que parecen tener, señalamos la relación entre juego y niños, pero no quisiéramos obviar la presencia que, si todo marcha bien, tiene el juego en la vida adulta.

El juego es búsqueda, señala Liberman4. Afortunadamente podemos jugar e imaginar 5 , porque imaginar nos permite estar en la vida, sentirnos reales, que como señala Winnicott (1971), es más que existir, y hacer frente a lo que muchas veces no podemos pensar o no somos capaces de comprender. Encauzamos y atenuamos la "dureza de vivir" gracias a la ensoñación, a la imaginación... que nos hacen el contacto con el sufrimiento más soportable (Sáinz Bermejo, 2017).

Levenson, valiéndose del concepto sullivaniano de la observación participante y en línea con la idea de que Los sucesos que aportan información son aquellos en los que participa el psiquiatra, no los que mira como si estuviera en lo alto de una torre de marfil (Mitchell, 2014), comprende que el terapeuta no está por fuera, sino que forma parte del proceso terapéutico, que no puede salir-se de la interacción: "No hay modo de estar con otra persona, incluso en la reserva analítica, sin interactuar con ella" (1983. Como se cita en Liberman, 2013).

Como decía Winnicott, "There is no such thing as a baby..." (1947), justificando esta impactante afirmación con la incuestionable certeza de la existencia siempre conjunta de un bebé y alguien cuidando de éste, "or at least a pram with someone's eyes and ears glved to it. One sees a 'nursing couple" ${ }^{6}$

Extrapolando la relación madre-bebé a la relación terapeuta-paciente, fácilmente comprendemos que el paciente no se observa en abstracto, sino afectado por nosotros: No hay un "objeto" aislado, está en un campo e influido por este. Nada... puede ser entendido fuera de su tiempo y lugar, de su nexo de relaciones. Es una falacia epistemológica pensar que podemos estar fuera de lo que observamos, o que observamos sin distorsión, lo que es ajeno a nuestra propia experiencia. (Levenson, como se cita en Mitchell, 2014).

Uno no puede ser impersonal con los niños (Guntrip, 1975), no puede limitarse a ser un mero "interprete técnico". En el juego, como en la terapia, participar implica estar. 


\section{\&o El (nuevo) lugar de la Transferencia y la Contratransferencia en Winnicott os}

La transferencia no podemos entenderla ya, de facto, como una resistencia. El paciente no se resiste, sino que (en línea con la segunda concepción de la resistencia de Freud) "repite algo sin saber qué fue".

Para Winnicott, el paciente requiere ciertas condiciones que el analista debe crear para que pueda tener lugar la transferencia como algo nuevo (punto dispar y característico vs Freud). El terapeuta no es un mero receptáculo de la transferencia (Sainz Bermejo, 2017), sino que es él mismo, su persona real, con su propia subjetividad, generador y en parte responsable de que ésta pueda desdoblar sus alas en la sesión.

Durante la despedida de una de sus sesiones, movido por su curiosidad, a un paciente adulto le había surgido una duda sobre un elemento de la decoración del hall del despacho donde trabajamos. En el inicio de la sesión siguiente, retomamos esta duda a la que, en la despedida de la sesión anterior, como el elemento en cuestión no era mío, no supe responder. En este segundo momento, sin embargo, alegre por poder responder-acompañar en algo de su curiosidad-exploración, pude comunicarle algo sobre este elemento. Esta respuestaacompañamiento elicitó en mí el recuerdo de una canción con la que jugaba a las palmas en mi infancia y espontáneamente le verbalicé esta idea y le canturreé la canción. A lo que él, creo igualmente espontáneo, pudo responderme canturreando también una canción de su infancia.

Supongo que por el estar genuino y sintonizado ( $y$ de algún modo tiernamente conmovido) de ambos, pudimos compartir un momento en que nuestras áreas transicionales se solaparon y en ese espacio compartido pudimos jugar.

Ferenczi, dice Gay (2010, pág 614), denunciaba en su diario la insensibilidad clásica y cómo tal actitud hace dudar al paciente de la realidad de sus sentimientos. Searles (1959), procurándole a la experiencia psicológica la profundidad que merece, señalaba algo parecido en los procesos interpersonales que tienden a enloquecer al otro, impidiéndole su desarrollo como persona. El sujeto se cuestiona la realidad percibida con sus propios ojos, entregándole al objeto una posición preferente. El sujeto que sucumbe a la esquizofrenia (o, sin necesidad de anclarnos en este extremo, al subyugamiento de un objeto enloquecedor) lo hace, en última instancia, procurando preservar el vínculo con cierto objeto. La relación del objeto enloquecedor con el sujeto enloquecido es el equivalente al asesinato psicológico. El amor genuino del pequeño por su madre es lo que provoca el sacrificio del desarrollo individual, del existir, en pos de la simbiosis que el objeto requiere para su propia existencia. 
Si podemos ser más nuestra persona real, estaremos más disponibles para el paciente, para brindarle lo que Winnicott denominaba <<relaciones vivas >> (que impliquen compromiso afectivo), para jugar con él y para tender los puentes que den lugar al solapamiento de áreas transicionales en la que podamos tener la experiencia compartida de sostén y reciprocidad. Tender a la construcción de una nueva relación bidireccional entre los dos integrantes del proceso, de una "díada relacional que se sostenga entre sí" (Sainz Bermejo, 2017).

Grolnick (1990. Como se cita en Abello y Liberman, 2011) afirma que para que pueda tener lugar la expresión del Self interno, de las "tripas", hace falta que el pequeño haya pasado por una experiencia de especularización en la cual el cuidador ha podido dar lugar y validez a la experiencia interna del niño. "El verdadero Self es, en parte algo dado y, en parte, requiere validación"7.

La idea Winnicottiana de que la terapia consiste en devolver al paciente lo que trae, a largo plazo, más que en hacer interpretaciones intelectualizadas es cardinal. Intentamos que el paciente se sienta reconocido y comprendido siendo él mismo (Sainz Bermejo, 2017), nos descubrirnos francos con él, le mostramos con sinceridad nuestros sentimientos. Interpretamos, como dice Winnicott, para que vea los límites de nuestra comprensión.

Lo que Coderch (2010) considera fundamental de la perspectiva relacional, y que sigue sin duda la senda dibujada por Winnicott, es poder ofrecerle al paciente la oportunidad, que le quedó negada en su infancia, de experienciar un proceso de desarrollo emocional en el setting de una relación confiable y beneficiosa.

Al inicio de Vivir Creativamente, Winnicott (1970) nos dice que independientemente de la concepción que tengamos de lo que es la creatividad,

...deberíamos incluir la idea de que la vida sólo es digna de vivirse cuando la creatividad forma parte de la experiencia vital del individuo. Y que Como quiera que fuere, nuestra teoría incluye la creencia de que vivir creativamente es un estado saludable, mientras que la complacencia [el sometimiento] es una base enferma para la vida.

En El uso de un objeto y la relación por medio de identificaciones, Winnicott (1969 [en 1979]) señala que para la mayor parte de las personas, el mayor elogio es ser descubierto y utilizado. Para esto es necesaria la presencia del otro. Cuando el terapeuta no puede estar, el trauma causado por la desilusión actual se vuelve más presente que la desilusión del pasado, colocándonos así en una posición retraumatizante.

La presencia del otro provoca que el presente sea contenedor del pasado y lo nuevo gana más fuerza que lo antiguo. La metamorfosis es cosa de dos. El terapeuta tiene que vivirse en la red relacional del paciente y juntos, han de trabajar "perforando desde dentro" (Levenson, 1988). Levenson (Como se cita en Liberman, 2011) nos obliga a pensar en el atravesamiento 
indiscutible y transformador de la relación terapéutica. A lo indefectiblemente indispensable de estar para el otro.

Cuando en la sesión se dan malentendidos, el analista elabora lo que él sintió, y crea con el paciente un nuevo lenguaje. Transforma lo que fue una experiencia invisible pero sentida, en un contexto psicológico que ambos puedan pensar y hablar. Una comprensión en la línea de lo que apunta Bollas (2009) cuando nos señala la necesidad de poder formular la existencia de un sentimiento antes incluso de que esté claro.

\section{0 ¿Por qué jugar? os}

Porque si con el adulto nos servimos de las palabras, con el niño nuestra vía regia es el juego (y la experimentación del otro) para procurar reparar la ruptura y ayudarle a metabolizar (probablemente espejear) y representar los <<estados de existir>> (Bollas, 2009. Capítulo 6) no transformados en retoños simbólicos o bien olvidados.

Jugamos porque jugar es universal, es comunicación, es lo natural, es salud y nos proporciona autocuración (Winnicott, 1982). Cuando un niño juega, observamos al niño que juega y vamos más allá del contenido y atendemos a las sutilezas que se nos comunican a través de este.

Cuando un niño (o un adulto) está jugando se muestra creador, por eso el juego es esencial, porque en él podemos usar "toda la personalidad, y el individuo descubre su persona sólo cuando se muestra creador" (Winnnicott, 1982, cap 4). Valeros (1997) lo indica claramente: Solo en el área de juego es posible la personificación o la individuación del ser humano.

El niño juega porque en el juego se desarrolla la seguridad en los recursos verdaderos de la persona y consecuentemente, una confianza mayor en los otros (Valeros, 1997).

Jugamos porque cuando el juego termina, somos capaces de integrar aspectos de nuestro sí mismo que estaban antes disociados (Valeros, 1997). Por ejemplo, ciertos aspectos de una paciente pequeñita podían quedar disociados en mí cuando jugábamos a su juego predilecto: yo era siempre una alumna tonta que lo hacía todo mal, que no se enteraba de nada y que finalmente tenía que decir que no sabía lo que había que hacer, porque "haga lo que haga siempre está mal". Mientras que la pequeña paciente jugaba actuando el rol de profe "mandona", que está en lo correcto siempre, que hace lo que hay que hacer, pero todo el rato tiene que decirle a la alumna que lo ha hecho mal y se cansa porque "no le queda otra que suspenderme". 
En el juego, con imágenes de disociaciones que no eran "de verdad" pero tampoco eran "de mentira", ella podía representar situaciones psicológicamente "en serio". A mí me daba para jugar el papel de la mala alumna, pero no se había deshecho de ese aspecto de sí misma. Mientras ella dirigía el juego, todo lo que sucedía era parte de ella. En el juego, ella podía observar y darle algo de sentido a la mala alumna que "yo soy" de igual manera que puede investigar y comprender a esa profe un poquito "mandona" que "es ella" y la relación de ella conmigo. Al jugar está representando su realidad psicológica, está dejándose llevar por "su necesidad y deseo de simbolizar su vida emocional" y en esto está implícita una ética preciosa, apunta Valeros (1997):

Todo lo que sucede en el juego es mío y soy yo.

Jugando, podemos "dejar en suspenso los juicios de la realidad convencional" pero no podemos deshacernos de la ética (Valeros, 1997). Cuando el juego termina, aprehende que maestra y alumna, son ella. Poco a poco esta pacientita pudo ir jugando a ser una profe que hacía juicios más amables con esa alumna que pudo ir haciendo las cosas mejor.

La persona que acude en busca de ayuda necesita una nueva experiencia de un marco especializado (un espacio en el que el terapeuta pueda permitir y sostener lo que Winnicott denomina "lo informe" ${ }^{8}$ ). Para que esto pueda tener lugar, el terapeuta debe aceptar la comunicación del paciente sin necesidad de organizarla, de lo contrario, el paciente abandona esa zona intermedia por la imposibilidad de comunicar lo insensato (el terapeuta no puede sostener lo informe).

No podemos ser perfectamente contingentes, el proceso de regulación mutua que se da en una díada abarca momentos de encuentro, desencuentro y reparación: en los momentos de contacto y sincronía entre la mamá y el bebé (terapeuta \& paciente) se producen rupturas que pueden ser reparadas, y la experiencia repetida de secuencias de reparación (así como de secuencias en las que el cuidador estuvo en coherencia con la experiencia del pequeño) permiten obtener un aprendizaje más allá de lo cognitivo: el conocimiento relacional implícito, la sensación de que los otros, así como uno mismo, son confiables ${ }^{9}$ (Beebe \& Lachmann, 1988). Gracias al encuentro, el paciente podrá "actuar como una unidad, no en defensa contra la ansiedad, sino como expresión del Yo Soy, estoy vivo, soy yo mismo" (Winnicott, 1982).

Freud dijo que "lo opuesto al juego no es aquello que es serio, sino lo que es real" y "por toda la alegría de su propia mente, siempre consideró el juego como un elemento constitutivo de la madurez" (Roazen, 1975). 
Winnicott (1982) nos elevaba un ruego a todos los terapeutas: "Permitan que el paciente exhiba su capacidad de jugar, es decir, de mostrarse creador en el trabajo analítico".

Las raíces de la psique se encuentran en la elaboración imaginativa del funcionamiento físico (Winnicott. Como se cita en Phillips, 1988). Esto es: El cuerpo es lo primero que se desarrolla -dice Freud (1915) que nuestros primeros recuerdos, los más profundos, son somáticos-, y sobre nuestra base corporal se asienta la psique. La psique se involucra en las relaciones (con los otros, con el cuerpo y con el mundo externo), y hace uso de la elaboración imaginativa, que es una fuerza vinculante implicada en las relaciones (Goldman, 2012) cuya coagulación de la experiencia que vamos acumulando sobre nuestra piel desde el momento en que nacemos, nos permite dotar de significado al sentido de sí mismo. La psique fragua lo que será la experiencia en sus tres tiempos (pasado, presente y futuro) y es quien dará sentido a nuestra percepción como individuos en nuestro propio cuerpo, cuya percepción es el elemento decisivo de la diferenciación y que puede estimular la toma de conciencia del Self corporal y de los otros (Lombardi, 2005. Como se cita en Lemma, 2014).

La realidad, dice Goldman (2012), que existe independientemente del individuo, no se imprime pasivamente, sino que es elaborada imaginativamente desde dentro. Como decía el poeta inglés Wordsworth "There is creation in the eye".

Señala Goldman (2012) el engranaje que parece haber entre ver y "ver en el ojo de la mente". Poco nos costaría encontrar la similitud entre este pensamiento y el que reflejan autores como Fonagy y Target (2006) cuando nos explica que el niño consigue un sentimiento de Self, aprende quién es, gracias a que la madre está disponible para prestarle su mirada y devolverle una imagen a través investida de amor y cuidado. El niño siente y aprende quien es por lo que la mamá refleja en su mirada, así da forma a la necesidad del bebé (de contener, de modular, de aliviar el impacto emocional de sus experiencias) ${ }^{10}$ y le otorga a su Self el sentimiento de que las cosas están "bien".

\section{¿ ¿Dónde empieza el jugar? os}

A cualquiera le es más fácil jugar cuando la otra persona puede y sabe ser juguetona (Winnicott, 1971). El jugar tiene un tiempo y un espacio, nos dice Winnicott (1971), no se encuentra dentro, tampoco fuera, sino en un tercer espacio. Los orígenes del jugar están en la relación madre-bebé motivada por el amor de la madre hacia éste (Winnicott, 1971), es la primera de todas y precursora de lo que será el futuro sujeto. El jugar tiene lugar en un estado de ilusión, cuando somos absolutamente dependientes y la experiencia de "dominio mágico del objeto" es una ilusión del bebé que debe sostener la madre. Después, en la dependencia 
relativa, cuando el otro ya tiene lugar, la ilusión de dominio es conseguida mediante la manipulación, siempre gracias a ese objeto dispuesto a sostener el juego y la realidad (Tagle, 2016).

Antes de abordar la infancia y el desarrollo temprano, Winnicott debía "conquistar un espacio que no existía" (Abello y Liberman, 2011). Partía del marco Freudiano, que podemos sintetizar con la famosa frase "His Majesty the Baby" (Freud, 1914, p. 88 [en Freud, 1997]). Freud había incluido la infancia dentro del campo de estudio, pero no se había dedicado a ella en profundidad. En sus escritos, aunque las características de la mirada de la madre sobre el bebé, en su expresión metafórica, tendrán fuertes repercusiones en el futuro del sujeto (Abello y Liberman, 2011) da por sentada la consecución de una base suficientemente sana para el desarrollo de la salud psíquica.

Winnicott se centrará en los primeros años de la infancia, en las relaciones "todavía más primitivas" (1958 [En 1999]). Enuncia la importancia y necesidad de los cuidados del bebé (que no están garantizados) y señala el ambiente como facilitador del desarrollo temprano. "El infante y el cuidado materno, juntos, forman una unidad" (Winnicott, 1965). Seguramente, su directo y prolongado contacto con madres y bebés como pediatra, influyó en la gestación de sus ideas, las cuales, apunta Painceira (1997, p.121), surgen "de la clínica", que es "desde la cabecera del paciente" y desde la vida misma.

Las cosas no vienen predeterminadas y el crecimiento del bebé puede verse truncado dependiendo del vínculo con el cuidador. El niño recién nacido que llega al mundo con vida es portador de <<el cetro de un primer ministro〉>, nos dirá Winnicott, sin embargo, en función de las características ambientales, ese cetro puede permanecer como algo que podría haber sido pero no fue (1970, p.339 [1991]).

\section{El encuadre $\operatorname{ss}$}

Hasta Winnicott, no hay teoría del encuadre (Green, como se cita en Abello y Liberman, 2011), pero para que todo lo que venimos señalando pueda tener lugar, hace falta un entorno con unas características especiales, una base que proporcione la contención suficiente.

Alessandra Lemma (2014) recuerda que, enmarcados en un modelo relacional, donde el analista tendrá que poner especial atención a la reacción del paciente con el marco y con los procesos internos, el analista debe ser el guardián del setting. Pero repara en el hecho de que cuando trabajamos, encontramos siempre dos settings: el que procura el analista y el que trae el paciente. Pudiendo ocurrir también que el cuerpo del analista sea parte del propio marco (Pág. 111-112). 
La persona que acude a sesión, apunta Winnicott (1982), necesita una nueva experiencia de un marco especializado. Para nuestro trabajo necesitamos un encuadre estable, pero lo más esencial, apunta Valeros (1997), es la estabilidad emocional del analista. Estos dos prerrequisitos, en conjunto, desencadenan un proceso natural de curación.

El marco es un contexto de seguridad que en su constancia otorga sustento, contención y acompañamiento. Las reglas del setting aportan seguridad (Lemma, 2014) (igual que las del juego). Mantener el setting que posibilite sostener la experiencia es responsabilidad del analista (como lo es del adulto, en la primera relación madre-bebé, proveer un entorno confiable al pequeño). Winnicott mismo apuntaba que un rasgo característico de su técnica cuando atendía en la consulta era el interés que sostenía por el juego en la relación de confianza que podía tener lugar entre el bebé y la madre (1982).

Igual que el encuadre nos facilita la búsqueda de sentido dentro del contexto de la sesión (Tangle, 2016), para jugar seguros, es mejor conocer de los límites, pero esto no implica una rigidez absoluta (a veces será necesario modificar el encuadre). Cada encuadre debe construirse con el paciente y procurar fomentar la consecución de un espacio que les permita el despliegue de un jugar creativo (Tangle, 2016),

Winnicott trabajó con pacientes con los cuales no podían darse por sentadas ciertas de las condiciones que Freud daba por supuestas cuando trabajaba en torno a las problemáticas neuróticas. Estos pacientes, cuyas fallas habían tenido lugar en épocas muy tempranas, sí que necesitaban poder llevar a cabo una regresión en terapia y en esta nueva clínica tiene lugar pensar el encuadre y entenderlo como proceso.

Para Winnicott (1958) el encuadre es una situación en la que se reproduce el maternaje que vivimos en nuestros inicios y, de igual modo que en estos, hay una fusión: el paciente y el encuadre se fusionan y se pone en juego el narcisismo primario. Civitarese (2008. Como se cita en Lemma, 2014. Pág 114), reparando en las cualidades del setting, señala: "A particular function of the setting is precisely that of providing a "skin" still in adhesive contact, with the role of integration"

Si todo marchó bien, el niño pudo crecer con la experiencia de ser sostenido y construir la creencia de que el mundo y él mismo son dignos de confianza. Si el niño no pudo gozar de un ambiente suficientemente bueno tendrá lugar lo que Winnicott denominaba la angustia impensable y un importante déficit en la adquisición de seguridad en sí mismo así como la fractura en el sentimiento de continuidad del propio Self (en el sentimiento de Going on Being). En estas situaciones, donde la falla fue tan temprana, el encuadre es proceso y será, 
como señalan Abello y Liberman (2011), el lugar en el que puedan tener lugar ciertas posibilidades de cambio.

El terapeuta se encuentra disponible para sostener la experiencia de ambos, pero sin olvidar la asimetría ${ }^{11}$. Aceptándola, libramos al paciente de la reciprocidad y simultáneamente velamos por no bloquear su autonomía (Ávila Espada, 2013).

Estas intervenciones flexibles podemos llevarlas a cabo si son potencialmente beneficiosas pero no alteran ni el funcionamiento profesional (la ética) ni la tolerancia del paciente Ávila Espada (2005). Si el vínculo terapéutico se configura como relación de objeto si-mismo, parece oportuno preguntarnos qué clase de experiencia de objeto brinda el "profesional" que se salta la ética. Por amor al paciente y a nuestra profesión, es nuestra obligación respetarla.

El marco es un proceso relacional. De igual manera que al principio de la vida nuestro sentido de sí mismo se adquiere en función del valor que nos otorga el ambiente, la respuesta del entorno-terapeuta será lo que otorgue sentido al gesto del paciente. Lo que se repite en las sesiones tiene que ser tramitado en el marco de una relación.

\section{sos Lo negativo os}

Andreé Green (2012) repasando las ideas apuntadas por Winnicott en Realidad y Juego, se detiene a señalar que la idea de "lo negativo" nace de los fenómenos transicionales. En 1971, Winnicott señala, la idea de una tolerancia limitada a la separación del objeto madre y la importancia de la separación y la pérdida. Del material clínico de Winnicott, recoge Green algo capital: <<El sentimiento mismo de la pérdida puede convertirse en una manera de integrar la autoexperiencia $>>^{12}$.

El objeto transicional es la primera posesión no-yo (un ejemplo de lo negativo en el desarrollo normal), se encuentra ubicado en una zona intermedia y al dar lugar a un tercer objeto, implica que algo no está presente. Este algo no presente es otra significación de lo negativo. Lo que procuramos señalar es como lo no presente / terciario / mediador/ transicional, se encuentra en el aquí y ahora de la sesión, tiene importancia clínica y relevancia más allá de la primera posesión no yo.

Repara Green (2012) en cómo, cuando Winnicott define lo transicional sirviéndose de una de sus paradojas ("no es un objeto utilizado, sino la utilización de un objeto"), comienza a esbozar lo que después será la tolerancia a lo negativo. El objeto transicional hace referencia al simbolismo en el tiempo, al viaje del bebé hacia la experiencia vivida. 
El espacio transicional, es un espacio entre otros dos, donde el futuro objeto está "en tránsito". Aquí virará lo negativo, pudiendo ocurrir que se transforme, de algo inherente del desarrollo psíquico en aquello que encontramos en casos patológicos. En 1951, Winnicott señaló la importancia de la ausencia en la zona transicional cuando hablamos de la psicopatología. La desaparición de la representación interna es lo que relaciona Green con la representación interior de lo negativo, esto es: la representación de la ausencia de representación. Lo negativo se expresa en términos de vacío (afecto), futilidad, pérdida de sentido. Remite a la falta, a la ausencia de memoria, a la ausencia en la mente, a la ausencia de contacto, a la ausencia del sentimiento de vida. Lo específico es olvidado, ha perdido su realidad. Lo negativo no es reprimido, es la ausencia, el vacío, es la falta, el agujero, la brecha, aquell que está fuera del alcance. Esto que no está, es el hecho real'13. Nuestra tarea aquí es encontrar, acoger, reconocer lo ausente procurando así transformar en terreno de juego el peor de los desiertos (Michel Leiris. Como se cita en Winnicott, 1982).

Painceira (1997, p.97) refiriéndose a lo negativo señala como: "La mayoría de lo que se dice acerca de la muerte se refiere a este primer estado anterior a la vivacidad en el cual la vivacidad, es un hecho antes de toparse con la dependencia".

Winnicott (1974), habla del desmoronamiento (breakdown), de la amenaza de éste que el sujeto sufre ubicándola en el futuro. No obstante, tal amenaza ha tenido ya lugar en el pasado. Se hace difícil aquí no pensar en M. Little y en su "Angustia Psicótica y Contención". No es un contenido reprimido ni latente, no es algo borrado por la censura, no toparemos con un trauma ni con una huella mnémica inscrita en la psique, como señala Pontalis en el prólogo de Realidad y Juego (1982).

He aquí otra de las magníficas paradojas Winnicottianas: este desmoronamiento que se teme que tenga lugar en el futuro "ha tenido lugar sin haber encontrado su lugar psíquico; no ha quedado registrado en ninguna parte". "Ha tenido lugar algo que carece de lugar". Así, la presencia - ausencia (de este agujero) testimonia lo no - vivido y ese miedo nos refiere a la ausencia, al vacío (Green, 2012).

Para acabar siendo quienes somos, partimos de una no-integración primaria: Al principio hay no-integración, no hay ligazón alguna entre el cuerpo y la psique y no hay lugar para una realidad distinta de mi (Winnicott, 1979). Partimos de una soledad esencial, Llegamos al mundo en un estado en el que no hemos entrado aún en la vida, dice Painceira (1997). La integración se refiere al funcionamiento bien articulado de la unidad psico-física, a la dimensión temporal, a la relación con el espacio, con el propio cuerpo y con la realidad exterior (Abello y Liberman, 2011, cap. 2). Es un proceso y un logro de ser en el propio cuerpo. 
La conquista hacia la integración (psique-soma) hace referencia, a cómo "el niño tiene que apropiarse de aquello que resulta de su relación con la madre" (Green, 2012).

La ausencia de contacto, incluso con la madre presente (Green, 2012), da lugar a la materialización de un vínculo ausente, es decir, negativo. Cuando el niño vive la ausencia de la madre, ésta ausencia es traumatizante (es incomprensible) y esta mamá, para el bebé, está muerta, por lo que es imposible restablecer el contacto cuando ella regresa ${ }^{14}$.

En el proceso normal de desarrollo psíquico los objetos reales sobreviven a la agresividad, gracias a lo cual el sujeto puede vivir una vida en el mundo de los objetos. Esto es lo que da lugar a la autonomía y a la vida. Los objetos, que son destruidos porque son reales, se vuelven reales porque son destruidos (Winnicott, 1969).

La idea central de Winnicott (1969) es que la destrucción es la que crea la realidad, ya que ubica el objeto fuera de la persona. El sujeto crea al objeto, encuentra la exterioridad. El éxito de esta empresa depende de la capacidad del objeto de sobrevivir ${ }^{15}$. Si todo esto marcha bien, el sujeto es capaz de colocar al objeto en una zona fuera del control omnipotente. La dupla ataque-supervivencia es la que forma la realidad y proporciona el sustento para el amor a un objeto real. El niño no destruye coléricamente al objeto, sino que muestra alegría por su supervivencia. Es a partir de este punto que el objeto siempre es destruido en la fantasía. Es necesario que el niño pase por esto para que pueda usar al objeto ${ }^{16}$.

\section{\&o Cómo estar con un niño cuando puede jugar en terapia $\mathcal{B}$}

Antes que nada, recordando que el juego es placentero. Khan, en la introducción de Holding and Interpretation: Fragment of an Analysis (Winnicott, 1986) rescata la respuesta de Winnicott ante la pregunta que le formulan unos sacerdotes anglicanos para saber cómo diferenciar si la persona que acude a ellos en busca de ayuda necesita la suya o la de un profesional de la salud mental. Winnicott les responde:

'If a person comes and talks to you and, listening to him, you feel he is boring you, then he is sick, and needs psychiatric treatment. But if he sustains your interest, no matter how grave his distress or conflict, then you can help him alright.'

En esta misma introducción, Khan continúa desarrollando esta idea y defiende que:

"It is my hypothesis here that boring has the quality of the 'anti-social tendency' (Winnicott 1956) and implies a demand and a hopefulness, whereas boredom is an organised and defensive mood and a psychic structure". 
Khan concluye con sus observaciones sobre el cansancio y el aburrimiento entendiendolos como estrategias del paciente para lidiar con su malestar interno.

Winnicott, con su singular sensibilidad, se preguntaba por la autenticidad del paciente, desde ahí Khan (Winnicott, 1986) nos anima a pensar aquello que es aburrido como verdaderamente inauténtico, tanto para el paciente como para el analista.

Algo similar nos cuenta Valeros (1997), cuando nos habla de las trampas que a veces tienen lugar en el juego de los niños. Cuando el pequeño hace trampas lo principal no es la agresión, sino el intento de reparación del Self. Así como dramatiza en el juego no reglado, también mediante el uso de las reglas puede armar una situación dramática. Visto así, "no es hacer trampa", sino que se trata de un despliegue del narcisismo infantil grandioso exhibicionista. El niño se está sincerando, es casi una confesión y un pedido, como si nos dijese:

Necesito, a la manera de un niño de dos años, desplegar mis aspiraciones personales de ser fuerte, de poder realizar mis aportaciones, desarrollar mis habilidades, ser admirable, responsable, reconocido. [...] Además, cuando yo desempeñe el rol del que puede, del que triunfa, del que gana, vos, analista, tendrás que representar el rol de mi Self desvalido, defectuoso, impotente, sufriente.

El pequeño nos mira para que confirmemos su gol. Lo que ocurre generalmente es que vemos con mayor facilidad "al niño trasgresor" que nos hace sentir ofendidos, y nos cuesta más ver al pequeño que nos invita a celebrar con él su auto-reparación. Esto ocurre, nos explica Valeros (1997), porque todo ser humano tiene un niño dentro de sí y cuando el pequeño "nos hace trampa", hiere nuestro propio narcisismo infantil [...] que queda desvalido (ante la trampa).

Que seamos "adultos" no nos previene de sentir el impacto emocional que las trampas generan, porque el narcisismo infantil no se cura ni se supera, es un componente normal de toda la vida. Los sentimientos personales no son exclusivos de la infancia, son normales y nos acompañan a lo largo de toda nuestra vida (Valeros, 1997) ${ }^{17}$.

Winnicott (1971) formula una idea bien conocida ya: "playing is itself a therapy"18. El efecto terapéutico del juego, como señala Lenormand (2018), puede provocar una transformación subjetiva solo cuando el experienciar del sujeto puede serle devuelto en un área compartida.

El juego es Mucho Más, no es cualquier cosa. La concepción del juego de Winnicott añade la importancia de experienciar toda la personalidad, y cómo esto permite al sujeto descubrir lo que es más intrínsecamente suyo, su Self (Su ipsidad). Lo que Winnicott denomina la sensación de estar vivo. expresa. Este material es para uso científico y profesional exclusivamente y puede contener información clínica sensible. Los editores no se responsabilizan de los contenidos de los autores. Dirigir las consultas sobre derechos y autorizaciones a ceir@psicoterapiarelacional.es 
Como ya nos apuntaba, el individuo puede "cohesionarse" y existir como unidad como una expresión de I am, I am alive, I am Myself (Winnicott, 1971).

La experiencia de creatividad del juego remite a la capacidad de vivir creativamente, haciendo uso de todo nuestro Self y no solo de partes de nuestra personalidad. ${ }^{19}$

La creatividad para Winnicott implica que "en cada uno de nosotros existe una vida secreta que es satisfactoria porque es original" (1971). Lo opuesto al vivir creativamente sería vivir con partes amputadas, sumido en la conformidad a la que nos vemos forzados por el ambiente que acarrea la creación de un falso Self.

La creatividad es universal, pertenece al ser que "está vivo", es "el hacer que surge del ser", es la espontaneidad y la integración de todas las partes involucradas en la personalidad (eróticas y agresivas) (Winnicott, 1971, 1986 b).

\section{\&os Jugar es Mucho Más us}

Antes de Winnicott, la técnica de juego apareció como una solución para el análisis de niños, (Lenormand, 2018) (aunque como ya hemos señalado, el juego no es exclusivo del niño), sin embargo, el juego en Winnicott tiene una dimensión que va más allá de su comprensión como una "técnica"; abrió la oportunidad para pensar el juego, el lugar de la interpretación, de la experiencia del paciente y la función del analista, para entender el lugar en el que ambos coinciden y la necesidad (innegociable) de que el segundo sea capaz de jugar, ya sea el paciente pequeño o adulto. Como afirma Lenormand (2018), la teoría del juego tiene impacto en el propio análisis.

Para Winnicott, el juego es un vehículo de la esperanza (Lenormand, 2018). Antes de él, el pesimismo kleiniano impregnaba el juego y no había diversión en él (Hinshelwood 1989, como se cita en Lenormand, 2018).

La clave para entender el playing Winnicottiano es estar en sesión sabiendo que el núcleo es la experiencia. El foco no está el contenido del juego, cuyos elementos latentes aspiramos a interpretar, sino que es en el jugar mismo donde descansa la clave de este. El juego permite al niño en el aquí y ahora de la sesión ensayar nuevas soluciones y atreverse a experimentar nuevas experiencias. El paciente no necesita una explicación, decía Winnicott (1971) sino una nueva experiencia "sin trabajo interpretativo" en un marco especializado.

Ofrecer esta nueva experiencia implica que habremos de sostener lo informe, lo repetitivo, la fuerza con que la libido se liga al objeto. Hacerle saber al paciente que no nos destruye, 
permitirle ser creativo, acompañarle en el uso que pueda hacer de nosotros, y que finalmente pueda sentir que está vivo: "Here at last I had a mother who could value her child"20.

El efecto terapéutico emerge entre los componentes de la díada del descubrimiento de la experiencia de algo nuevo y de una relación con el mundo y con uno mismo que hasta ese momento era estaban aún por descubrir (Lenormand, 2018).

Que el analista juegue es la clave principal para poder llevar acabo la terapia. Jugar es una cosa muy seria. No es una cuestión técnica, solo podemos jugar cuando podemos ser genuinos. La clave está en poder comprender el impacto emocional que tiene el paciente sobre el terapeuta, ya que la comprensión de la respuesta afectiva del terapeuta nos permite encontrar el espacio desde el cual el jugar es posible y natural (Valeros, 1997).

¿Cuál es la razón para que nos entreguemos al juego? El juego ayuda a la digestión de las experiencias, opera de manera similar a como lo hace el sueño, reparando las heridas del ánimo que durante el día se mantendrían siempre abiertas (Purkinje, 1846. En Freud, 1990). Igual que el sueño, el juego nos proporciona reparo y necesitamos la ilusión que nos brinda. Winnicott se percató de esos objetos "con superpoderes" que usamos de pequeños y los denominó objetos transicionales (1951). Son los que ayudan al bebé a salir de "el mundo de los sueños" (Tangle, 2016) que primeramente habita y a salir de su narcisismo primario. Estos objetos quedarán ubicados en un espacio que ni es ya interno, ni aún externo. Su espacio será la zona intermedia. Se trata de una creación que se mantiene en una condición de indiferenciación interno-externo en un estado especial de conciencia que denominamos estado de ilusión. Jugamos en ese tercer espacio, que no es ni interno ni externo, a través del estado de ilusión. En una zona intermedia entre la creatividad subjetiva y la realidad objetiva (Green, 2012).

Green (2012), entendiendo que los fenómenos transicionales (que son resultantes de la separación) pertenecen a los fenómenos de simbolización, los incluye en lo que él denomina procesos terciarios, "mediadores entre los procesos primarios y secundarios; son esenciales para la elaboración psicoanalítica". Es esa tercera zona intermedia la que nos permitirá atender a experiencias nucleares de la infancia como el juego. Para poder habitar su mundo interno (Tangle, 2016), tendrá que hacerlo a través del estado de ilusión. Si el niño puede explorar mediante el juego, en ese territorio indefinido que hemos acotado como transicional, se le abre la oportunidad de que algunas de las mociones del mundo interno logren representarse entrando en escena, y se aproximen de esta forma a la posibilidad de ser integradas por el yo (Tangle, 2016).

Lo terapéutico del juego no se limita al alivio de los síntomas, tiene un efecto más profundo: la transformación de la relación con uno mismo, con los otros y con el mundo (Lenormand, 
2018). Con suerte la terapia será un lugar suficientemente seguro para atreverse a explorar y el niño puede desarrollar un jugar espontáneo y elaborativo, que se origina y reaparece siempre en el seno de, y sostenido por, el vínculo con otro (Tangle, 2016). Así es como los niños comienzan a jugar, cuando encuentran a alguien disponible que sostenga el escenario de juego y a su vez se ocupe de la realidad del entorno.

Para que podamos jugar necesitamos estar concentrados, porque el juego nos requiere estar desentendidos de la realidad circundante. El cine, el teatro o un libro que nos sos-tiene cautivos son algunas de las opciones que nos brinda nuestra cultura para poder disfrutar también de este estado especial en el que la realidad queda fuera $y$, cuando se filtra, es una interferencia (Tangle, 2016).

El juego, dice Valeros (1997): ...implica aceptar, ver, crear, encontrar, descubrir alternativas dentro de pautas [...] ya establecidas.

Confiamos en que jugar muchas veces, estar con el otro de esa otra manera, investigando nuevas opciones, re-descubriendo y (re-)creando el mundo muchas veces, provoca que finalmente, en el paciente, se decante una función de sostén y se salvaguarde este espacio intermedio. Con esto, se irá equipando para poder jugar solo, aunque acompañado por el sedimento interno de las innumerables experiencias en las que la presencia y disponibilidad del objeto fue externa y real (Tangle, 2016).

\section{REFERENCIAS}

Abello. A., \& Liberman, A. (2011). Una introducción a la obra de D. W. Winnicott: contribuciones al pensamiento relacional. Ágora Relacional.

Ávila Espada, A. (2005). Al cambio psíquico se accede por la relación. Intersubjetivo: revista de psicoterapia psicoanalítica y salud, 7(2).

Ávila Espada, A. (2009). Pensando sobre el cambio. Comentario al trabajo de Joan Coderch Neurociencias y modelo relacional., Clínica e investigación relacional, 3 (1), 54 - 57

Ávila Espada, A. (2013). La relación, contexto determinante de la transformación. Reflexiones en torno al papel de la interpretación, el insight y la experiencia emocional en el cambio psíquico. Temas de Psicoanálisis, 6.

Ávila Espada, A. (2013). La tradición interpersonal. Madrid: Ágora Relacional.

Balint, M. (1982). La Falta Básica. Buenos Aires: Editorial Paidós

Beebe, B., \& Lachmann, F. M. (1988). The contribution of mother-infant mutual influence to the origins of self-and object representations. Psychoanalytic psychology, 5(4), 305. 
Bollas, C. (2009). La sombra del objeto: psicoanálisis de lo sabido no pensado (2 ${ }^{a}$ Ed). Buenos Aires: Amorrortu.

Coderch, J. (2007). Conflicto, déficit y defecto. Clínica e investigación relacional, 1(2), 359-371.

Coderch, J. (2010). La práctica de la psicoterapia relacional: El modelo interactivo en el campo del psicoanálisis. Ágora Relacional. Madrid.

Ferenczi, S. (1988). Confusion of tongues between adults and the child: The language of tenderness and of passion. Contemporary psychoanalysis, 24(2), 196-206.

Fonagy, P., \& Target, M. (2006). The Menatalization-Focused Approach to Self Pathology. Journal of Personality Disorders, 20(6), 544-576.

Freud, S. (1915) Lo Inconsciente. En Sigmund Freud, Obras Completas (Tomo XIV). Buenos Aires: Amorrortu.

Freud, S. (1920). Más allá del principio del placer. En Sigmund Freud, Obras Completas (Tomo XVIII). Buenos Aires: Amorrortu Editores.

Freud, S. (1997). Introducción al Narcisismo. En Sigmund Freud, Obras Completas (Tomo XIV). Buenos Aires: Amorrortu Editores. (Versión original de 1914).

Gay, P. (2010). Freud: vida y legado de un precursor. Paidós.

Goldman, D. (2012). Weaving with the world: Winnicott's re-imagining of reality. The Psychoanalytic Quarterly, 81(1), 1-23.

Green, A. (2012). Jugar con Winnicott. Amorrortu Editores.

Guntrip, H. (1975). My Experience of Analysis with Fairbairn and Winnicott-(How Complete a Result Does Psycho-Analytic Therapy Achieve?). International Review of Psycho-Analysis, 2:145-156

Lemma, A. (2014). Minding the body: The body in psychoanalysis and beyond. Routledge.

Lenormand, M. (2018). Winnicott's theory of playing: a reconsideration. The International Journal of Psychoanalysis, 99(1), 82-102.

Liberman, A. y Abello, A. (2008). Winnicott hoy, su presencia en la clínica actual. Madrid: Ed Psimática.

Liberman, A. (2013). Edgar A Levenson, una voz a los márgenes. En: Ávila Espada, A. La tradición interpersonal. Perspectiva social y cultural en psicoanálisis. Madrid: Ágora Relacional.

Liberman, A. (2011). Exposición y comentario del trabajo de Mitchell: Cuando la interpretación falla: una nueva mirada sobre la acción terapéutica en psicoanálisis. Aperturas psicoanalíticas: Revista de psicoanálisis, (37), 8.

Levenson, E. A. (1988). The pursuit of the particular: On psychoanalytic inquiry. Contemporary Psychoanalysis, 24, 1-16.

Mitchell, S. A. (2014). Influence and autonomy in psychoanalysis. Routledge.

Painceira, A. (1997). Clinica Psicoanalitica a partir de la obra de Winnicott. Buenos aires, Argentina. Lumen.

Phillips, A (1988). Winnicott. Fontana Modern Masters. 
Roazen, P. (1975). Freud and his followers. Da Capo Series

Sainz Bermejo, F. (2017). Winnicott y la perspectiva relacional en psicoanálisis. Herder Editorial.

Searles, H. F. (1959). The effort to drive the other person crazy-an element in the aetiology and psychotherapy of schizophrenia. Psychology and Psychotherapy: Theory, Research and Practice, 32(1), 1-18.

Sharp, C., \& Fonagy, P. (2008). The parent's capacity to treat the child as a psychological agent: Constructs, measures and implications for developmental psychopathology. Social Development, 17(3), 737-754.

Tangle, A., (2016) Del juego a Winnicott: Una revolución silenciosa, Ciudad Autónoma de Buenos Aires, Lugar Editorial.

Winnicott, D. W. (1947). Hate in the Countertransference. En Winnicott, D. W. (1975). Through paediatrics to psycho-analysis: Collected papers. Brunner/Mazel.

Winnicott, D. (1951). Las necesidades del niño y el papel de la madre en las primeras etapas. El niño y el mundo externo.

Winnicott, D. (1958). Metapsychological and Clinical Aspects of Regression within the Psychoanalytical Set-up. En Through paediatrics to psycho-analysis. Londres: Karnak

Winnicott, D. (1969), El uso de un objeto y la relación por medio de identificaciones.

Winnicott, D. W. (1965). The Theory of the Parent-Infant Relationship. En The Maturational Processes and the Facilitating Environment. Londres: Karnak.

Winnicott, D. (1970). Vivir creativamente. El hogar, nuestro punto de partida. Ensayos de un psicoanalista, 48-65.

Winnicott, D. W. 1971. Playing and Reality. London: Routledge. [Winnicott, D. W. (1982). Realidady juego. Barcelona: Ed Gedisa.]

Winnicott, D. W. (1974). Fear of Breakdown. International Review of Psycho-Analysis, 1, 103-107.

Winnicott, D. (1979), Escritos de Psiquiatría y Psicoanálisis. Barcelona: Laia.

Winnicott, D. W. (1986). Holding and Interpretation. Fragment of an analysis. London: Karnac.

Winnicott, D. W. (1986,b). Home is Where we Start From. Edited by Winnicott, C., R. Shepherd, and M. Davis. London: Norton and Company.

Winnicott, C. (1991). Individuación. En Exploraciones Psicoanalíticas I. Buenos Aires: Paidós (versión original de 1970).

Winnicott, D. W. (1999) Primitive Emotional Development. En Winnicott, D. W. (1958). Through Pediatrics to Psychoanalysis. Londres: Karnak. (versión original de 1945)

Winnicott, D. W. (2007). La asistencia en internados como terapia. En D. Winnicott, Obras escogidas: Deprivación y delincuencia. Tomo III. (pp. 228 - 236). Barcelona: RBA. (Versión original de 1970).

Original recibido con fecha: 11/11/2019 Revisado: 30/12/2019 Aceptado: 15/03/2020 
NOTAS:

\begin{abstract}
${ }^{1}$ Infante, literalmente "el que no puede hablar". No al menos este lenguaje que usamos los adultos. Su lenguaje es el lenguaje de la ternura (Ferenczi, 1988).

${ }^{2}$ Quedarnos en este nos aboca a la retraumatización y nos coloca en el lugar del analista iatrogénico que es incapaz de acoplarse y vibrar en sintonía con su paciente.

3 Winnicott subraya la importancia del proceso de reunión y separación, al salirse creativamente de estas dos opciones, crear una nueva ubicada entre ambas, que será un espacio de reunión potencial. Poder ubicarnos en ese momento, señala Green (2012), nos abre las puertas a una concepción más dinámica y más enriquecida del simbolismo en la que el objeto es encontrado, por oposición a perdido, y creado, por oposición a percibido.
\end{abstract}

${ }^{4}$ Liberman. A., Comunicación personal. 2018.

5 Imaginar, que no fantasear. Así distingue Winnicott (1971) los procesos ligados al vivir, a los sueños, a la libertad, a la vida y al juego creador (esto es imaginar) de los procesos inaccesibles, encerrados, más próximos al polo disociativo y sin valor simbólico (fantasear).

${ }^{6}$ Para enriquecer todavía más la mirada, Green (2012) agregará que la relación madre-hijo tampoco existe. La finalidad de ésta afirmación es recalcar que si obviamos al padre estamos de nuevo sucumbiendo a una perspectiva algo simplista, ya que, aunque al comienzo el bebé se relacional prácticamente de manera exclusiva con la madre, sería ingenuo por nuestra parte asumir que durante ese periodo el padre "no existe". "La cualidad de una relación suficientemente buena de parte de la madre depende del amor de la madre por el padre y recíprocamente, aún cuando la relación del niño con el padre parece mínima, comparada con el vínculo con la madre, en los primeros tiempos de la vida". "El padre está co-presente con la madre y ausente (relativamente) para el niño, y aunque pueda tener una relación corporal con él, al comienzo no es un objeto distinto, y esta relación no es en absoluto comparable a la de la madre" (p. 111, 113).

7 Winnicott, reflexionando sobre el Self, escribe: Para mí el Self, que no es el ego, es la persona que yo soy, y solamente yo, que posee una totalidad basada en el proceso madurativo. Al mismo tiempo, el self tiene partes y está constituido por ellas. Estas partes se aglutinan en una dirección interior-exterior en el curso del proceso madurativo auxiliadas según el caso (en un grado máximo al comienzo) por el ambiente humano, que sostiene [holds] y manipula [handles] y, de una manera viva, facilita (Abello y Liberman, 2011. Pág 185).

${ }^{8}$ Winnicott (1971. Cap2) utiliza un bonito símil para ilustrar este concepto, refiriéndose a la tela para un vestido antes de ser cortada.

9 Una paciente de Winnicott, justo en la dirección opuesta, nos brinda un ejemplo de lo que ocurre cuando las cosas no marchan bien y el sentimiento que llega sobre la base de un estado no integrado se pierde cuando no hay nadie digno de confianza disponible para observarlo y reflejarlo. En referencia al "primer trauma" (palabras de Winnicott), la paciente comenta: "Supongo que una herida tendría que repetirse muchas veces para que su efecto fuese tan profundo" (Winnicott, 1982. Cap 4).

${ }^{10}$ La madre mentaliza cuando es capaz de proporcionarle al niño un encuentro de mentes (Sharp, y Fonagy, 2008).

${ }^{11}$ De igual manera que nos hacemos eco de la bidireccionalidad, parece capital señalar la asimetría en la díada terapéutica (Ávila, 2009) y no dejar de recordar que la regulación mutua no implica simetría.

${ }^{12} \mathrm{~A}$ pesar de que al inicio de su conceptualización lo negativo se liga a la estructura patológica (Winnicott, 1971), a medida que el concepto continúa desarrollándose, la comprensión de Winnicott sobre éste fue evolucionando ligado al desarrollo normal (Green, 2012).

${ }^{13}$ Como en el caso del paciente que relata Green (2012) en el que "la manta que no está es más real que la que está".

${ }^{14}$ Winnicott hablaba de dos extremos, por un lado existía la muerte de la madre cuando estaba presente y por otro la muerte de la madre cuando no estaba en condiciones de reaparecer (de volver a la vida). En este segundo caso, la separación es irreversible.

${ }^{15}$ Entendiendo la supervivencia del objeto como que éste no tome represalias. 
${ }^{16}$ No hablamos de uso como aprovechamiento, entendemos que el sujeto puede relacionarse con el objeto o usarlo. Cuando el sujeto se relaciona lo hace con un objeto subjetivo. Usarlo implica que el objeto forma parte de la realidad exterior

${ }^{17}$ Fairbairn, en una ocasión le dijera a Guntrip que era incapaz de pensar qué podría motivar a ninguno de los que nos volvemos terapeutas para tal fin, salvo que todos hemos tenido nuestros propios problemas (Guntrip, 1975).

${ }^{18}$ Que la experiencia de descubrimiento de la cohesión de su propio cuerpo fuera creativa, propició un efecto terapéutico en la niñita (es decir, que sus síntomas desaparecieron).

${ }^{19}$ Hablando de vivir creativamente, un bonito ejemplo pudiéramos encontrarlo en las palabras de la surfera Hawaina Keila Moniz cuando dice "Surfing is a extensión of yourself".

${ }^{20}$ Palabras de Guntrip (1975) refiriéndose a su análisis con Winnicott. 